\title{
KAJIAN ALAT TANGKAP MINI TRAWL NELAYAN PULAU TINGGI DESA PENUTUK KECAMATAN LEPAR PONGOK KABUPATEN BANGKA SELATAN
}

\section{STUDY OF MINI TRAWL IN PULAU TINGGI PENUTUK, LEPAR PONGOK, SOUTH BANGKA}

\author{
Alias Pikal, Kurniawan* dan M. Bachtiyar \\ Program Studi Manajemen Sumberdaya Perairan Universitas Bangka Belitung \\ Kampus Terpadu UBB, Gedung Teladan, Desa Balunijuk, Kepulauan Bangka Belitung, 33172 Indonesia \\ Email : awal.rizka@yahoo.com
}

\begin{abstract}
ABSTRAK
Mini Trawl masuk dalam klasifikasi pukat hela dimana cara pengoperasiannya dengan cara ditarik oleh kapal yang bergerak mengejar gerombolan ikan. Penelitian ini dilaksanakan pada bulan Februari sampai Maret 2019 di Pulau Tinggi Desa Penutuk Kecamatan Lepar Pongok Kabupaten Bangka Selatan. Penelitian ini bertujuan untuk mengetahui wilayah penangkapan ikan oleh nelayan mini trawl, mengidentifikasi alat tangkap, mengidentifikasi hasil tangkapan dan aspek kondisi ekonomi nelayan mini trawl yang ada di Pulau Tinggi Kabupaten Bangka Selatan. Metode penelitian ini menggunakan metode deskriptif dengan jenis metode survei meliputi aspek kontruksi alat tangkap, wilayah penangkapan dan hasil tangkapan. Hasil Penelitian menunjukan bahwa daerah penangkapan ikan mini trawl berada pada dua perairan yaitu Perairan Karang Pelawang dan Perairan Pasir Putih. Identifikasi kontruksi alat tangkap mini trawl adalah sayap jaring, badan jaring, kantong jaring, papan rentan, tali ris atas dan bawah, tali selambar, pemberat dan pelampung. Identifikasi hasil tangkapan didapatkan 8 jenis spesies yang tertangkap yaitu udang jerebung (Fenneropeanus merguienis), selar (Selar crumenophtahalmus) kurisi (Nemipterus furcosus), pepetek (Leiognathus equulus), ikan cermin (Alectis indica), kuda laut (Hippocampus cuvier) dan buntal(Legochepalus fugu).
\end{abstract}

Kata Kunci : mini trawl, identifikasi, aspek ekonomi, nelayan.

\begin{abstract}
Mini trawls are included in the classification of trawls with using the method of operation by means of being pulled by a moving ship chasing a group of fish. This research was conducted in February 2019 to March 2019 at Pulau Tinggi of Lepar Pongok South Bangka. The purpose of this research is to know fishing ground, identification of mini traw contruction, identification catch and aspects of fishermen economic conditions of mini trawl. Methode of the research was interview survey. The analysis of the research was descriptive analysis. The result showed that the location of fishing ground is two location are Karang Pelawang waters and Pasir Putih Waters. The Identification of fishing tools of mini trawls there are wing of nets, belly, otter board, cod end, head rope, ground rope, warp rope, float and sinker. There are 8 spesies fish caught, the local name are Jerebung shrimp (Fenneropeanus merguienis), Selar fish (Selar crumenophtahalmus), Kurisi fish (Nemipterus furcosus), Pepetek (Leiognathus equulus), Cermin fish (Alectis indica), kuda laut (Hippocampus cuvier) dan Buntal fish(Legochepalus fugu).
\end{abstract}

Keywords : mini trawl, identification, economic aspect, and fisherman.

\section{PENDAHULUAN}

Provinsi kepulauan Bangka Belitung merupakan daerah kepulauan dengan luas wilayah perairan $65.301 \mathrm{~km}^{2}$ mencapai 4 kali dari seluruh luas wilayah daratannya 16.281 $\mathrm{km}^{2}$. Kabupaten Bangka Selatan merupakan salah satu pusat kegiatan perikanan tangkap di Provinsi kepulauan Bangka Belitung. Produksi penangkapan ikan laut di Kabupaten
Bangka Selatan pada tahun 2009 mencapai 20.121.725 ton (Dinas Kelautan dan Perikanan Provinsi, 2005).

Desa Penutuk Pulau Tinggi merupakan salah satu desa yang berada di Kecamatan Lepar Pongok Kabupaten Bangka Selatan. Kecamatan Lepar Pongok merupakan kecamatan pesisir yang terletak pada posisi $02^{\circ} 59^{\prime} 13.67^{\prime \prime}$ LS dan $106^{\circ} 42^{\prime} 6.23^{\prime \prime}$ BT dengan luas wilayah $169,3 \mathrm{~km}^{2}$ dan panjang 
pantai 2.787,892 m. Potensi perikanan tangkap menjadi potensi unggulan di kecamatan ini.

Alat tangkap trawl masuk dalam klasifikasi pukat hela menurut peraturan Menteri Kelautan dan Perikanan No 6 tahun 2010 tentang klasifikasi alat penangkap ikan di WPP RI. Menurut Peraturan Menteri Kelautan dan Perikanan No 2 tahun 2015 tentang pelarangan penggunaan alat tangkap pukat hela dan pukat tarik di WPPRI alat tangkap Trawl merupakan alat tangkap yang dilarang. Penggunaan alat tangkap ini dapat mengancam kelestarian sumberdaya ikan. Alat tangkap mini trawl di Kecamatan Lepar Pongok merupakan salah satu alat tangkap yang digunakan untuk menangkap udang sebagai hasil tangkapan utama. Hasil tangkapan sampingan berupa ikan demersal, kerang dan cumi-cumi. Diestimasikan jumlah hasil tangkapan sampingan mini trawl jauh lebih besar dibandingkan dengan jumlah tangkapan utama (Direktorat Jenderal Perikanan, 1995).

Kebutuhan data informasi yang akurat terkait perikanan tangkap sangat diperlukan dalam pengelolaan pemanfaatan sumberdaya perikanan. Persebaran daerah tangkapan dan kontruksi alat tangkap mini trawl di Pulau Tinggi belum diketahui, bagaimana persebarannya hingga jarak tempuh menuju daerah penangkapan.

Penelitian tentang fishing ground serta kontruksi alat tangkap mini trawl yang ada di Pulau Tinggi sangat penting untuk dilakukan, sebagai data awal informasi ilmiah yang akan memberikan gambaran dalam pengelolaan perikanan di Kabupaten Bangka Selatan. Maka perlu adanya penelitian mengenai fishing ground alat tangkap mini trawl Pulau Tinggi Desa Penutuk Kecamatan Lepar Pongok Kabupaten Bangka Selatan.

\section{METODE PENELITIAN}

Identifikasi sampel yang diperoleh dari lapangan dilakukan di Laboratorium Perikanan Fakultas Pertanian, Perikanan, dan Biologi Universitas Bangka Belitung.

Metode penelitian ini menggunakan metode deskriptif dengan jenis metode survei meliputi aspek kontruksi alat tangkap, wilayah penangkapan dan hasil tangkapan. Data yang dikumpulkan dalam penelitian ini terdiri atas data primer dan data sekunder. Data primer dikumpulkan berupa titik koordinat yang diambil langsung dilapangan dan melalui wawancara langsung terhadap nelayan dengan kuesioner yang telah disiapkan sebelumnya meliputi kontruksi alat tangkap, hasil tangkpan dan kondisi ekonomi nelayan. Data sekunder yang dikumpulkan meliputi jumlah nelayan alat tangkap mini trawl dan dan peta zonasi perairan Kabupaten Bangka Selatan.

Teknik metode sensus, dengan jumlah responden sebanyak 13 nelayan, metode yang digunakan dalam penentuan jumlah responden ialah menggunakan metode sensus, maka peneliti dapat mewawancarai seluruh nelayan mini trawl yang ada.

Identifikasi jenis ikan menggunakan metode Identifikasi dilakukan sampai tingkat genus dan spesies dengan bantuan buku identifikasi Saanin (1968), Allen (1999), dan software identifikasi ikan fishbase.

Studi dokumentasi adalah memperoleh data melalui peninggalan tertulis seperti arsip-arsip dan termasuk juga buku-buku tentang pendapat, teori-teori atau hukumhukum dan lain-lain yang berhubungan dengan masalah penelitian.

\section{Analisis Data}

Analisis data dalam penelitian ini akan dituangkan dalam bentuk deskriptif yaitu menggambarkan, menguraikan dan menganalisis semua data penelitian yang diperoleh. Teknik pengolahan data yang digunakan adalah setelah data terkumpul dari hasil penelitian kemudian ditabulasi dan dideskripsikan dalam bentuk tabel. Pengklasifikasian jenis alat tangkap menggunakan KEPMEN KP No 6 tahun 2010 dan FAO (Kurniawan, 2019). Alat tangkap yang digunakan oleh nelayan akan di klasifikasikan dan disajikan dalam bentuk tabel.

\section{HASIL DAN PEMBAHASAN}

Berdasarkan hasil penelitian didapatkan wilayah fishing ground alat tangkap mini trawl di dua perairan yaitu perairan pasir putih dan perairan karang pelawang dapat di lihat pada Gambar 1.

Wilayah fishing ground alat tangkap mini trawl di Pulau Tinggi didapatkan wilayah penangkapan alat tangkap mini trawl berada di 2 lokasi yang berbeda. Lokasi penangkapanpertama berada di wilayah perairan Pasir Putih dengan titik koordinat $03^{\circ}$ $07^{\prime} 306^{\prime \prime} \mathrm{S}$ dan $106^{\circ} 42^{\prime} 955^{\prime \prime} \mathrm{E}$ sampai $03^{\circ} 07^{\prime}$ $65^{\prime \prime} \mathrm{S}$ dan $106^{\circ} 42^{\prime} 17.14^{\prime \prime}$ E. Kemudian pada lokasi penangkapan kedua berada di wilayah Karang Pelawang dengan titik koordinat $2^{\circ}$ $55^{\prime} 32.65^{\prime \prime} \mathrm{S}$ dan $106^{\circ} 41^{\prime} 43.26^{\prime \prime} \mathrm{E}$ sampai $2057^{\prime} 18.65^{\prime \prime} \mathrm{S}$ dan $106^{\circ} 40^{\prime} 28.16^{\prime \prime} \mathrm{E}$. Daerah tangkapan nelayan Pulau Tinggi 
merupakan daerah perairan yang dangkal dan memiliki substrat pasir berlumpur yang memiliki kedalaman perairan antara 3-10 meter.

Wilayah penangkapan nelayan Pulau Tinggi pada perairan Pasir Putih didiapatkan nelayan yang beroperasi di perairan ini adalah sebanyak 5 kapal, hal ini didukung oleh perairannya yang cukup luas untuk melakukan kegiatan penangkapan. Menurut Areba (2017) mengatakan bahwa wilayah perairan Pasir Putih merupakan wilayah penangkapan bagi nelayan mini trawl untuk nelayan kecamatan Lepar Pongok. Hal ini dikarenakan wilayah perairan Pasir Putih memiliki substrat pasir berlumpur, dimana pada substrat ini banyak terdapat ikan dan udang. Hal ini sesuai menurut Nontji (2008) yang mengatakan bahwa pada substrat pasir berlumpur merupakan habitat bagi ikan kecil dan krustacea seperti ikan pepetek dan udang, karena pada substrat ini merupakan tempat mencari makan bagi hewan kecil seperti ikan dan udang.

Lokasi penangkapan kedua yaitu pada perairan Karang Pelawang dengan titik koordinat yaitu $2^{\circ} 55^{\prime} 32.65^{\prime \prime} \mathrm{S}$ dan $106^{\circ} 41^{\prime}$ 43.26". Wilayah ini berada pada sebelah utaranya Pulau Tinggi, nelayan biasa menyebutnya dengan wilayah perairan Lepar. Pada wilayah Karang Pelawang didapatkan nelayan yang beroperasi disana sebanyak 3 kapal. Wilayah Karang Pelawang sendiri adalah wilayah penangkapan ikan yang luas perairanya sedikit sempit. Hal ini menyebapkan sedikitnya nelayan yang melakukan operasi penangkapan ikan di perairan Karang Pelawang. Perairan Karang Pelawang memiliki substrat pasir berlumpur, dimana pada substrat ini banyak terdapat ikan dan udang. Hal ini sama seperti wilayah Perairan Pasir Putih

\section{Identifikasi Kontruksi Alat Tangkap Mini Trawl}

Berdasarkan hasil identifikasi kontruksi alat tangkap mini trawl dapat dilihat pada Tabel 3.

\section{Identifikasi Kontruksi Alat Tangkap Mini Trawl}

\section{Badan Jaring}

Berdasarkan hasil wawancara dan melihat langsung alat tangkap mini trawl di Pulau Tinggi, jaring mini trawl yang digunakan nelayan Pulau Tinggi adalah
Polyethilene $(P E)$ dengan ukuran mesh size sebesar $2,5 \mathrm{~cm}$ dan panjang badan jaring mencapai 7 meter dengan pintalan jaring yaitu pintalan $Z$. Ukuran ini sangat sesuai digunakan nelayan mini trawl Pulau Tinggi yang rata- rata memiliki ukuran kapal sebesar 3 GT untuk menangkap hasil tangkapan di daerah yang dangkal seperti pada perairan Pasir Putih dengan hasil tangkapan utama berupa udang dan tangkapan sampingan berupa ikan pepetek.

\section{Kantong Jaring}

Berdasarkan hasil yang didapatkan bahwa bahan kantong jaring nelayan mini trawl Pulau Tinggi adalah Polyethylene dengan ukuran mesh size mata jaring adalah $1 \mathrm{~cm}$ atau $10 \mathrm{~mm}$ dan panjang kantong jaring sebesar 2 meter dengan pintalan jaring yaitu pintalan $Z$. Kantong jaring di desain lebih kecil dari pada badan jaring, mulai dari ukuran mata jaring hingga panjang jaring. Hal ini dikarenakan fungsi dari kantong jaring itu sendiri sebagai tempat menampung hasil tangkapan, agar hasil tangkapan tidak mudah Iolos.

\section{Papan Rentang}

Papan rentang atau papan otter digunakan untuk mengupayakan agar sayap jaring terbuka kekanan dan kekiri. Ukuran papan rentang yang digunakan oleh nelayan mini trawl Pulau Tinggi berukuran panjang bekisar 1 meter dan lebar $50 \mathrm{~cm}$ dengan berat satu buah papan rentang berkisar $10 \mathrm{~kg}$ yang memiliki ketebalan berkisar $7 \mathrm{~cm}$. Hal ini berbeda menurut (Zarochman et al, 1993) yang menyatakan bahwa secara umum papan rentang memiliki ukuran $40 \mathrm{~cm} \times 80 \mathrm{~cm}$ dan berat papan rentang berkisar $6 \mathrm{~kg}$. Dari penelitian ini pada nelayan mini trawl Pulau Tinggi memiliki modifikasi pada alat tangkapnya khususnya pada papan rentang. Modifikasi yang dilakukan nelayan mini trawl Pulau Tinggi meliputi penambahan berat dan panjang pada papan rentang.

\section{Tali Ris Atas Dan Tali Ris Bawah}

Ukuran Tali ris atas biasanya sama dengan ukuran tali ris bawah berkisar 4 inci, ukuran tali ini jauh lebih besar dibandingkan dengan tali pada badan jaring dan tali jaring kantong (Ditjen Perikanan, 1995). Bahan pada tali ris atas dan tali ris bawah adalah Polyethilene $(P E)$. Panjang dari tali ris atas dan tali ris bawah berkisar 6 meter dengan pintalan $Z$ dan memiliki diameter sebesar 5 $\mathrm{mm}$ dengan berat masing 2 tali adalah $7 \mathrm{~kg}$. 

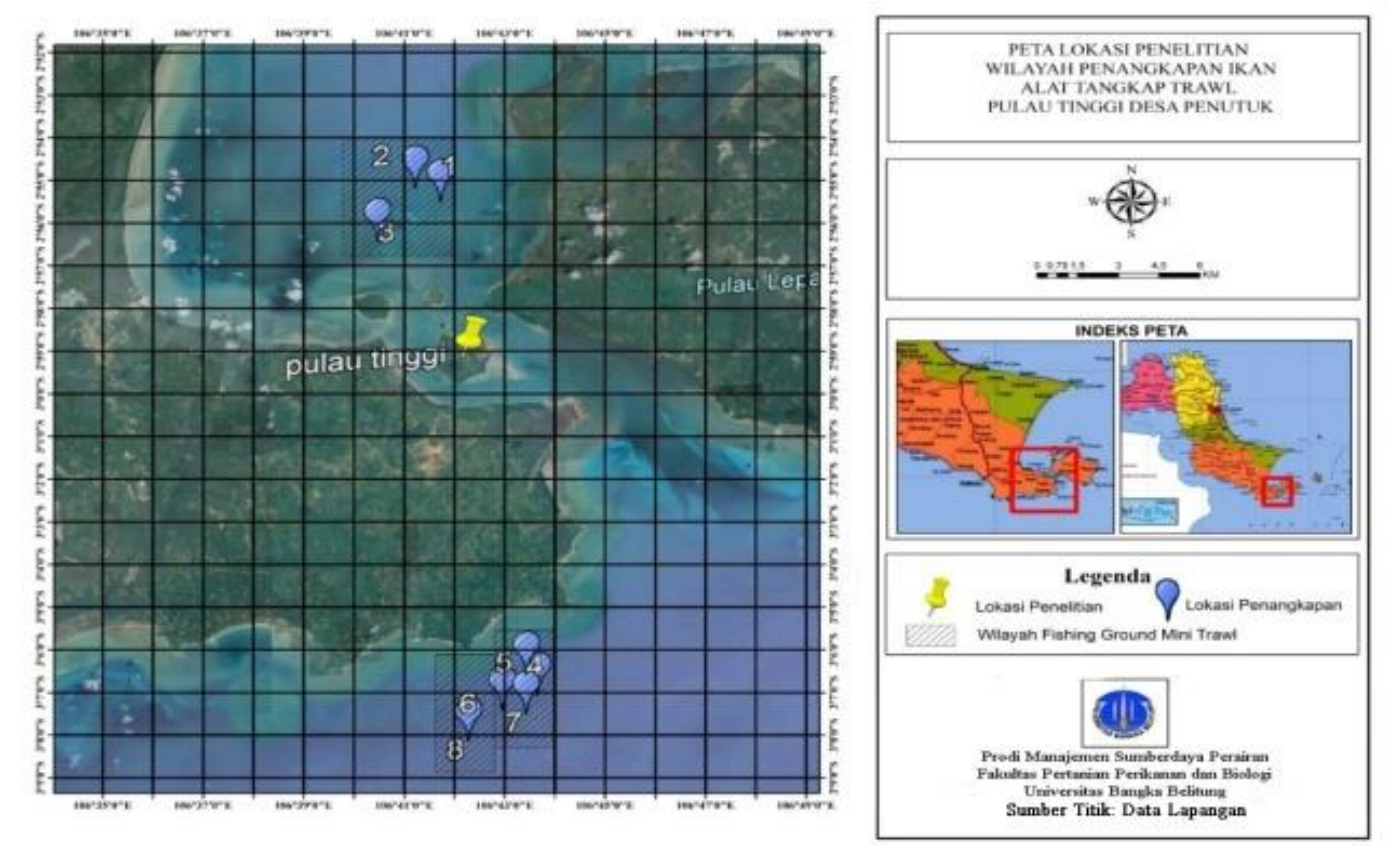

Gambar 1. Wilayah Fishing Ground Alat Tangkap Mini Trawl Sumber : Google Earth

Tabel 3. Dimensi Alat Tangkap Mini Trawl Pulau

\begin{tabular}{|c|c|c|c|c|c|c|c|}
\hline No & Bagian & Bahan & $\begin{array}{l}\text { Berat } \\
(\mathrm{kg})\end{array}$ & $\begin{array}{c}\emptyset \\
(\mathrm{mm})\end{array}$ & Pintalan & $\begin{array}{c}\text { Panjang } \\
\text { (m) }\end{array}$ & $\begin{array}{c}\# \\
\text { Mesh } \\
\text { Size } \\
(\mathrm{cm})\end{array}$ \\
\hline 1 & Sayap & $\begin{array}{l}\text { Polyethile } \\
\text { ne (PE) }\end{array}$ & - & - & Z & 3 & 2 \\
\hline 2 & $\begin{array}{l}\text { Badan } \\
\text { Jaring }\end{array}$ & $\begin{array}{l}\text { Polyethile } \\
\text { ne (PE) }\end{array}$ & - & - & Z & 7 & 2,5 \\
\hline 3 & $\begin{array}{l}\text { Kantong } \\
\text { Jaring }\end{array}$ & $\begin{array}{l}\text { Polyethile } \\
\text { ne (PE) }\end{array}$ & - & 8 & Z & 2 & 1 \\
\hline 4 & $\begin{array}{l}\text { Papan } \\
\text { Rentang }\end{array}$ & $\begin{array}{l}\text { Kayu } \\
\text { Papan }\end{array}$ & 10 & - & - & 1 & - \\
\hline 5 & $\begin{array}{l}\text { Tali Ris } \\
\text { Atas }\end{array}$ & $\begin{array}{l}\text { Polyethile } \\
\text { ne }(P E)\end{array}$ & 7 & 5 & Z & 6 & - \\
\hline 6 & $\begin{array}{l}\text { Tali Ris } \\
\text { Bawah }\end{array}$ & $\begin{array}{l}\text { Polyethile } \\
\text { ne (PE) }\end{array}$ & 7 & 5 & $\mathrm{Z}$ & 6 & $=$ \\
\hline 7 & $\begin{array}{l}\text { Tali } \\
\text { Selamba } \\
\text { r }\end{array}$ & $\begin{array}{l}\text { Polyethile } \\
\text { ne (PE) }\end{array}$ & - & 5 & Z & 4 & - \\
\hline 8 & $\begin{array}{l}\text { Pelampu } \\
\text { ng }\end{array}$ & $\begin{array}{l}\text { Polyvinile } \\
\text { Cloida } \\
\text { (PVC) }\end{array}$ & 0,2 & 70 & - & - & - \\
\hline 9 & $\begin{array}{l}\text { Pembera } \\
\mathrm{t}\end{array}$ & Rantai & 8 & 2 & - & - & - \\
\hline
\end{tabular}


Tabel 4. Identifikasi Hasil Tangkapan Utama

\begin{tabular}{|c|c|c|c|c|c|c|c|c|}
\hline No & Gambar/ foto & $\begin{array}{l}\text { Nama } \\
\text { Ikan }\end{array}$ & Genus & Family & Spesies & $\begin{array}{l}\text { Jumlah } \\
\mathrm{kg}\end{array}$ & Dimanfa atkan & Dibuang \\
\hline 1 & & $\begin{array}{l}\text { Udang } \\
\text { Jerbung }\end{array}$ & Caridea & metapenaeus & $\begin{array}{l}\text { Fenneropeamus } \\
\text { merguienis }\end{array}$ & 15 & $\sqrt{ }$ & - \\
\hline
\end{tabular}

Tabel 4. Identifikasi Hasil Tangkapan Sampingan

\begin{tabular}{|c|c|c|c|c|c|c|c|c|}
\hline No & Gambar/ foto & Nama Ikan & Genus & Family & Spesies & $\begin{array}{l}\text { Jumlah } \\
\text { hasil } 3 \\
\text { kali trip }\end{array}$ & $\begin{array}{l}\text { Dimanfaatka } \\
\mathrm{n}\end{array}$ & Dibuang \\
\hline 1 & & Kunisi & $\begin{array}{l}\text { Nemipt } \\
\text { erus }\end{array}$ & $\begin{array}{l}\text { Nemipter } \\
\text { idae }\end{array}$ & $\begin{array}{l}\text { Nemipter } \\
\text { us } \\
\text { furcosus }\end{array}$ & 14 & $\sqrt{1}$ & - \\
\hline 2 & & Selar & $\begin{array}{l}\text { Selaroi } \\
\text { des }\end{array}$ & $\begin{array}{l}\text { Carangid } \\
\text { ae }\end{array}$ & $\begin{array}{l}\text { Selar } \\
\text { crumeno } \\
\text { phtahalm } \\
\text { us }\end{array}$ & 16 & $\sqrt{ }$ & - \\
\hline 3 & & Pepetek & $\begin{array}{l}\text { leiogna } \\
\text { thus }\end{array}$ & $\begin{array}{l}\text { Leiognat } \\
\text { hidae }\end{array}$ & $\begin{array}{l}\text { Leiognat } \\
\text { hus } \\
\text { equulus }\end{array}$ & 615 & $\sqrt{ }$ & - \\
\hline 4 & & Kuda Laut & $\begin{array}{l}\text { Hippoc } \\
\text { ampus }\end{array}$ & $\begin{array}{l}\text { Syngnath } \\
\text { idae }\end{array}$ & $\begin{array}{l}\text { Hippoca } \\
\text { mpus } \\
\text { cuvier }\end{array}$ & 0.5 & - & $\sqrt{ }$ \\
\hline 5 & & Buntal & $\begin{array}{l}\text { Legoch } \\
\text { epalus }\end{array}$ & $\begin{array}{l}\text { Tetraodo } \\
\text { ntidae }\end{array}$ & $\begin{array}{l}\text { Legoche } \\
\text { palusfug } \\
u\end{array}$ & 7 & - & $\sqrt{1}$ \\
\hline 6 & & $\begin{array}{l}\text { Ikan } \\
\text { Cermin }\end{array}$ & $\begin{array}{l}\text { Alectiu } \\
\text { s }\end{array}$ & $\begin{array}{l}\text { Carangid } \\
\text { ae }\end{array}$ & $\begin{array}{l}\text { Alectis } \\
\text { indica }\end{array}$ & 0.5 & - & $\sqrt{1}$ \\
\hline
\end{tabular}

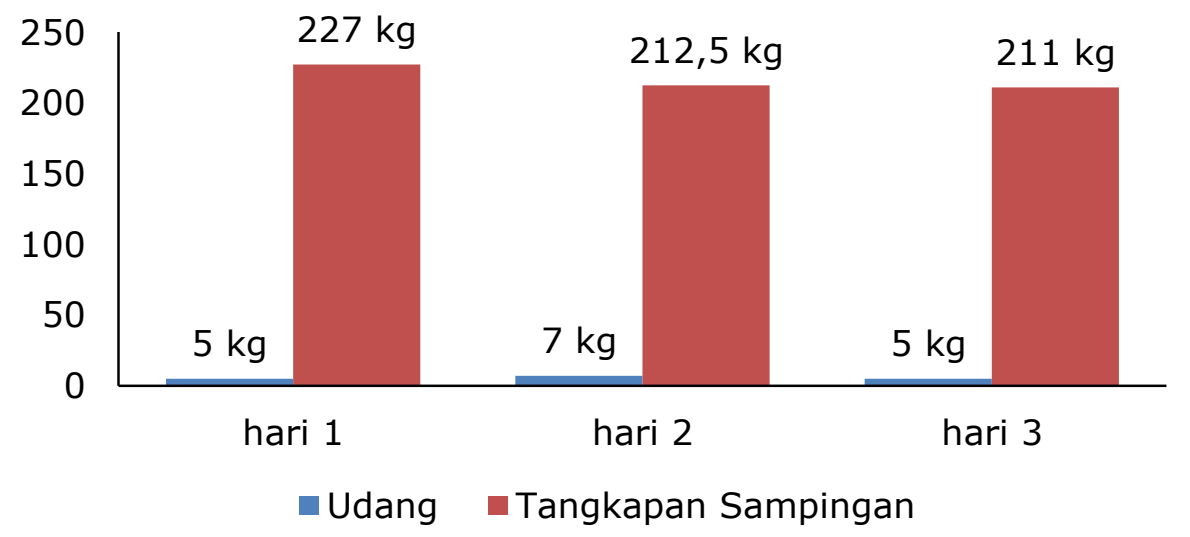

Gambar 4. Perbandingan Hasil Tangkapan

\section{Pelampung}

Pelampung digunakan untuk membantu agar mulut jaring terbuka keatas. Pelampung yang digunakan nelayan mini trawl Pulau Tinggi adalah Polyvinile Cloida (PVC), dengan dimeter pelampung adalah sebesar $70 \mathrm{~mm}$ dan berat dari satu pelampung ialah mencapai 2 ons dengan jumlah keseluruhan pelampung yang digunakan ialah sebanyak 12 buah pelampung. Rata-ratapelampung yang digunakan nelayan trawl di Kabupaten Bangka Sekatan ialah pelampung berbahan 
Polyvinile Cloida (PVC), karena pelampung ini mudah didapatkan pada tempat penjualan perlengkapan alat tangkap yang ada di Kabupaten Bangka Selatan

\section{Pemberat}

Pemberat digunakan untuk membantu membuka mulut jaring ke dasar perairan. Pemberat yang digunakan nelayan mini trawl Pulau Tinggi adalah berbahan rantai besi terdiri dari 6-7 ring rantai pada setiap rantai. Bobot keseluruhan dari rantai yang digunakan nelayan mini trawl di Pulau Tinggi adalah sebesar $8 \mathrm{~kg}$ dengan diameter rantai per ringnya adalah sebesar $2 \mathrm{~mm}$. Dari informasi yang didapatkan dari nelayan bahwa pemberat yang digunakan nelayan mini trawl didapatkan dari bengkel yang ada di daerah sekitar Kabupaten Bangka Selatan.

\section{Identifikasi Hasil Tangkapan Ikan Alat Tangkap Mini Trawl}

Hasil identifikasi tangkapan nelayan mini trawl didapatakan 7 spesies ikan yang tertangkap yaitu Udang (Fenneropeanus merguienis), Kurisi (Nemipterus japonicus), Selar (Selarcrumenohtah almus), Pepetek (Leiogognathus aquulus), Kuda Laut (Hippocampus cuvier), Buntal (Legochepalus fugu), Ikan Cermin (Alectis indica). Komposisi hasil tangkapan sampingan yang paling banyak didapatkan adalah pada spesies Ikan Pepetek (Leiogognathus aquulus) dengan hasil tangkapan berkisar 200-250 kg dengan nilai komposisinya sebesar 20,5\%.Hal ini sesuai menurut Nontji (2002) mengatakan bahwa operasi penangkapan menggunakan kapal pukat ataupun dengan bagan bisa memperoleh ikan pepetek dalam jumlah yang sangat besar. Hasil tangkapan utama ialah udang sedangkan hasil tangkapan sampingan adalah selaian udang. Hasil tangkapan sampingan adalah semua hasil tangkapan selain tangkapan utama. Tangkapan sampingan biasanya dimanfaatkan nelayan untuk dikonsumsi sendiri selain itu juga ada juga tangkapan sampingan yang dijual ke masyarakat atau nelayan lainnya seperti nelayan pancing dan nelayan keramba jaring apung. Tidak semua tangkapan sampingan dapat dimanfaatkan, ada pula tangkapan sampingan yang dibuang. Hasil tangkapan sampingan yang dimanfaatkan berupa ikan Pepetek (Leiogognathus aquulus), Kurisi (Nemipterus japonicus), Selar (Selarcrumenohtah almus). Ikan Pepetek (Leiogognathus aquulus) dimanfaatkan oleh nelayan mini trawl untuk dijual ke pemilik keramba jaring apung dan kemasyarakat yang memiliki usaha yang terbuat dari daging ikan. Sedangkan spesies Kurisi (Nemipterus

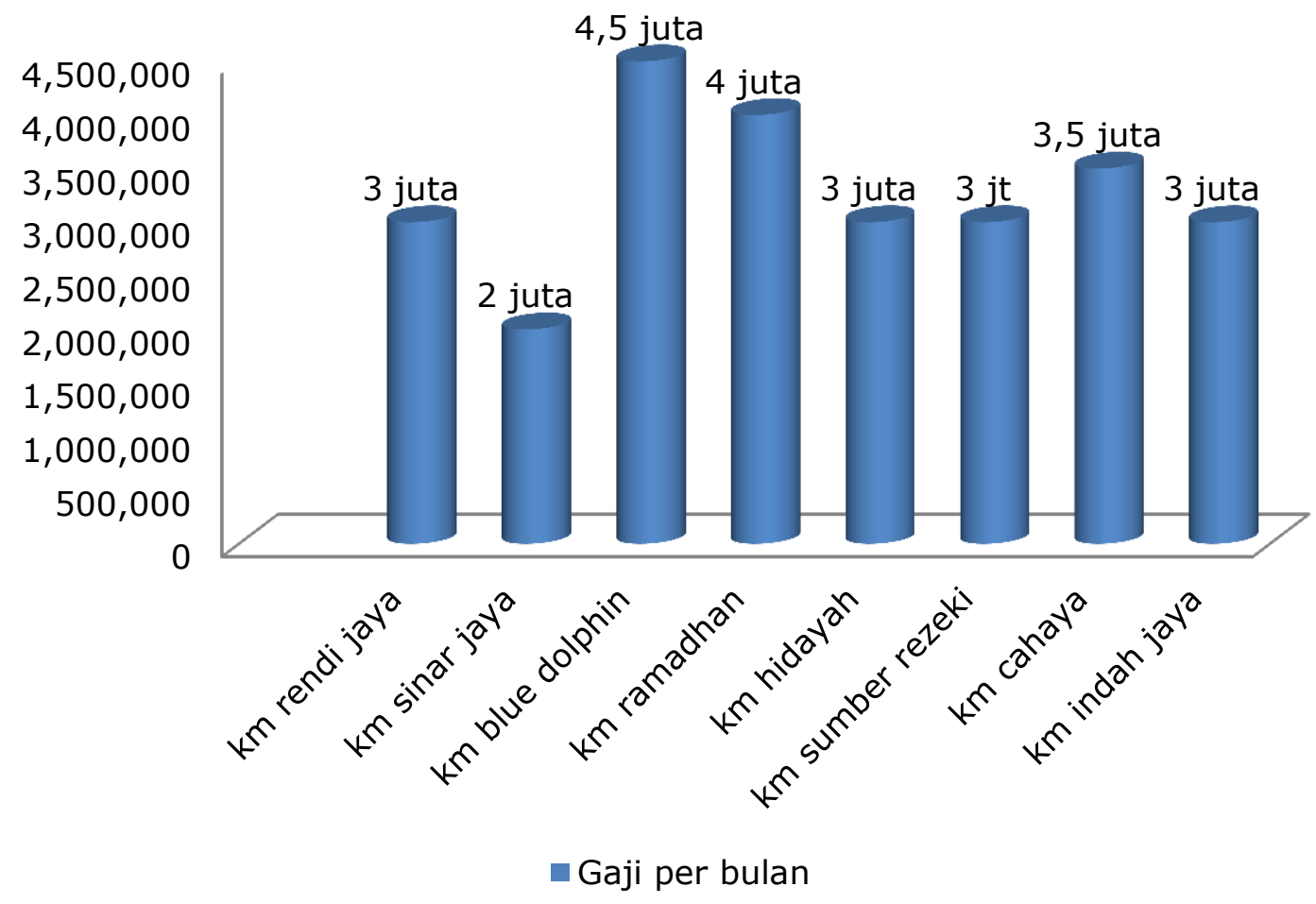

Gambar 5. Pendapatan Nelayan 
japonicus) dan Selar (Selarcrumenohtah almus) dimanfaatkan nelayan sebagai bahan konsumsi sendiri. Hasil tangkapan sampingan yang tidak dimanfaatkan atau dibuang biasanya spesies yang memiliki racun pada tubuh ataupun spesies yang masyarakat sendiri tidak tahu dalam pengolahannya seperti spesies Kuda Laut (Hippocampus cuvier), Buntal (Legochepalus fugu).

\section{Perbandingan Hasil Tangkapan Utama Dengan Tangkapan Sampingan}

Didapatkan perbandingan tangkapan utama dan tangkapan sampingan alat tangkap mini trawl Pulau Tinggi adalah hasil tangkapan utama lebih sedikit dibandingakan dengan hasil tangkapan sampingan. Hari pertama nelayan mini trawl mendapatkan hasil tangkapan utama sebesar $5 \mathrm{~kg}$ dan tangkapan sampingan $227 \mathrm{~kg}$, kemudian pada hari kedua nelayan mendapatkan hasil tangkapan utama sebesar $7 \mathrm{~kg}$ dan tangkapan sampingan sebesar $212,5 \mathrm{~kg}$, dan pada hari ketiga didapatkan hasil tangkapan utama sebesar $5 \mathrm{~kg}$ dan tangkapan sampingan $211 \mathrm{~kg}$.

Hasil tangkapan sampingan paling tinggi di dapatkan pada hari pertama, dan hasil tangkapan utama yang paling tinggi adalah pada hari kedua. Faktor yang mempengaruhi perbandingan hasil tangkapan ini adalah dilihat dari musim komuditasnya, biasanya pada bulan Februari sampai bulan Maret hasil tangkapan utama berupa udang sangat sedikit, hal ini disebabkan karena pada bulan Februari sampai dengan bulan Maret bukanlah bulan puncak penangkapan udang. Bulan puncak penangkapan udang biasanya berada pada bulan September, Desember dan Januari, karena pada bulan itu biasanya adalah musim barat, dimana musim barat adalah musim yang dikenal dengan musim ombak besar dan arus laut yang kuat. Hal ini menyebabkan udang berenang mendekati permukaan perairan karena arus laut menggerus dasar perairan yang menjadi tempat bersembunyi udang. Hal ini sesuai menurut Anggrioni (2018) yang mengatakan bahwa hasil tangkapan udang paling tinggi dilakuakan nelayan pada bulan Januari, September, Desember dan hasil tangkapan paling sedikit dilakukan pada bulan Februari, Mei, dan bulan Juni.

\section{Aspek Ekonomi Nelayan Alat Tangkap Mini Trawl}

Pendapatan total nelayan mini trawl didapatkan hasil paling rendah ialah sebesar
Rp. 2.000.000,00, sedangkan pendapatan paling tinggi adalah sebesar Rp. 4.500.000,00. Pendapatan bersih rata - rata nelayan mini trawl Pulau Tinggi per bulan ialah sebesar Rp. 3.250.000,00. Sedangkan pendapatan bersih nelayan mini trawl Pulau Tinggi per hari ialah sebesar Rp. 158.750,Pendapatan paling rendah didapatkan pada wilayah penangkapan Perairan Karang Pelawang. Hal ini dikarenakan upaya penangkapan pada Perairan Karang Pelawang lebih sedikit dibandingkan wilayah Perairan Pasir Putih. Upaya Penangkapan Pada Karang Pelawang sebanyak 3 buah unit kapal yang melakukan operasional, sedangkan pada Perairan Pasir Putih upaya penangkapannya sebanyak 5 unit kapal yang melakukan operasi penangkapan ikan.

Pendapatan bersih rata - rata nelayan mini trawl Pulau Tinggi per bulan ialah sebesar Rp. 3.250.000,00. Sedangkan pendapatan bersih nelayan mini trawl Pulau Tinggi per hari ialah sebesar Rp. 158.750,-.. Pendapatan nelayan Pulau Tinggi dapat dibandingkan dengan data NTN (nilai tukar nelayan) dari Kabupaten Bangka Selatan yang menunjukan NTN rata-rata pemilik pukat tarik tahun 2018 adalah 94 atau dibawah 100. Hal ini menunjukan pendapatan nelayan mini trawl di Pulau Tinggi dapat dikatakan belum mencukupi biaya melaut dan biaya hidup sehari-hari. Pendapatan nelayan selain dipengaruhi oleh banyaknya hasil tangkapan juga dipengaruhi oleh harga setiap kilogram. Semakin besar hasil tangkapan nelayan maka semakin besar pula pendapatan kotor yang diterima oleh nelayan pemilik.Pendapatan bersih pada suatu usaha tergantung pada penerima total dan biaya total yang dikeluarkan, apabila nelayan dapat menekan biaya-biaya produksi sekecil mungkin, maka pendapatan bersih yang akan diterima akan lebih besar dan begitu pula sebaliknya.

\section{KESIMPULAN}

Wilayah penangkapan nelayan mini trawl berada di dua wilayah perairan yang berbeda yaitu Perairan Pasir Putih dan Perairan Karang Pelawang. Identifikasi hasil tangkapan utama didapatkan 1 spesies yang tertangkap alat tangkap mini trawl yaitu Udang Jerbung (Fenneropeanus merguienis), tangkapan sampingan didapatkan 6 spesies yaitu Kurisi (Nemipterus japonicus), Selar (Selarcrumenohtah almus), Pepetek (Leiogognathus aquulus), Kuda Laut (Hippocampus cuvier), Buntal (Legochepalus 
fugu), Ikan Cermin (Alectis indica). Aspek ekonomi nelayan mini trawl didaptakan nilai rata-rata pendapatan bersih nelayan berkisar Rp. 3.250.000,00- per bulan dan rata-rata Rp. 158.750,00- per hari.

\section{REFERENSI}

Allen, G. 1999. Marine Fishes Of South-East Asia. Asia Pasific: Berkeley Books Pte Ltd.

Areba, L. 2017. Analisis Hasil Tangkapan Sampingan Nelayan Mini Trawl Pulau Panjang Bangka Selatan [Skripsi]. Program Studi Manajemen Sumberdaya Perairan Fakultas Pertanian Perikanan Dan Biologi. Universitas Bangka Belitung

Dinas Kelautan dan Perikanan Provinsi Bangka Belitung. 2005. Laporan Tahunan 2004. Pangkal pinang: Dinas kelautan perikanan.

Direktorat Jenderal Perikanan Tangkap. 1997. Jaring Trawl dan Jaring Yang Menyerupai Trawl Tetapi Bukan Trawl,

Juklak SK Mentan No.

503/Kpts/Um/7/1980

Khaerudin, A. 2006. Proporsi Hasil Tangkapan Jaring Arad (Mini Trawl) Yang Berbasis Di Pesisir Utara, Kota Cirebon [Skripsi]. Fakultas Perikanan Dan Ilmu Kelautan. Institut Pertanian Bogor. Bogor

Nontji, A. 2008. Laut Nusantara. Penerbit Djambatan. Jakarta.

Nuddin, H. 2000. Analisi Ekonomi Usaha Penangkapan Udang Dengan Trammel Net Di Kabupaten Pasuran, Jurnal Penelitian Ilmu-Ilmu Sosial, Fakultas Perikanan Universitas Brawijaya. 12(1)

Kurniawan, K. 2019. Keragaan Unit Penangkapan Ikan Di Kabupaten Bangka Selatan. Aquatic Science, $1(1): 20-32$.

Saanin, H. 1968. Taksonomi Dan Kunci Identifikasi Ikan Jilid I. Binacipta. Bogor.

Saanin, H. 1984. Taksonomi Dan Kunci Identifikasi Ikan Jilid II. Binacipta. Bogor. 